\title{
Instructional Creation Media Project Based for Mainstreaming of Undergraduate Students to Enhance 21st Century Learning
}

\author{
Titiya Netwong* \\ Faculty of Science and Technology, Suan Dusit University, Bangkok, Thailand. \\ * Corresponding author. Tel.: +66 89617 0526; email: titiya_net@dusit.ac.th \\ Manuscript submitted August 30, 2017; accepted October 30, 2017. \\ doi: 10.17706/ijeeee.2018.8.4.227-233
}

\begin{abstract}
The objectives of this research were to 1) study the direction to the instructional creation media project based for mainstreaming of undergraduate students to enhance 21st century learning. 2) To study the effects of using instructional creation media project based for mainstreaming of undergraduate students to enhance 21st century learning. The sample group in this study to divide by objectives of study as follows: 1) directors and experts consisted of 17 persons, 2) 61 undergraduate students; there were 54 normal students and 7 special need students. Students studied via the instructional creation media project based for mainstreaming of undergraduate students using for 13 weeks. Data were analyzed by using frequency, percentage, mean ( $\bar{X}$ ), standard deviation (S.D.), and t-test dependent. The results of this research were as follows: 1. the instructional creation media project based for mainstreaming of undergraduate students to enhance 21st century learning consisted of 5 components as follows: 1) prepare mainstreaming, 2) problem of communities or need to develop community by process project based, 3) learning of learner, 4) creation media, and 5) technology. The processing the learning activities that divided 6 process: 1) provided learner to mainstreaming, 2) offered knowledge and group activity, 3) reviewed knowledge, 4) knowledge application, 5) creative of media, and 6) the evaluate. 2. The undergraduate students post-test scores for 21st century learning as information, media and technology was appropriate in a high, level 4 ( $X=4.06$, S.D. $=0.41$ ) and significantly higher than pre-test scores at .05 significant level. The learning achievement of information, media and technology, after undertaking teaching was 22.61 , and development $43.42 \%$. The learning achievement of information, media and technology were significantly higher than pre-test scores at .05 significant levels.
\end{abstract}

Key words: Creation media project based, mainstreaming, 21st century learning.

\section{Introduction}

The 21st century is the era of the new skills to development of learners as individuals, the quality person of the learning process. To the growth of individuals and society by the knowledge, transfer training workshops cultural heritage. Enhancement academic progress, the knowledge that comes from learning and social environment factors contribute to individual learning continues throughout life long learning. Education should be based on that. All students are able to learn and develop themselves, and those considered to the most important. The education must encourage students to develop their full potential and natural. [1] So learning in the 21st century requires teaching strategies that focus on the learners. The 
students participate the interaction can create a self-taught style of teaching and the teaching of science in the process. The curriculum focuses on giving students the opportunity to do, the students to apply knowledge in new situations. By teaching strategies and processes used to enhance learning in the 21st century. Teachers need to use information and information technology to be used in the event of instruction to enhance learning for students. Learning activities are integrated. The students learn in practice. Teachers need to change the role of teaching presenters, as coaching and facilitator for the students to learn deeply. The instructors teach less, the students have learned more from the problems outside the classroom or community learning together as a team, and links. Assess the progress of their learning, self-esteem, and inspire of them. [2], [3]

Said that teaching to enhance learning in the 21st century requires the integration of a variety of teaching techniques processes. This learning by using project based, one option is to develop the learning of students. So learning by using project based learning, it is learned that promotes lifelong learning. This is consistent with theories of learning such as self-learning, constructivism and collaborative learning or cooperative learning. By way of learning, start the process of acquiring knowledge and skills to solve problems in the form of learning as well. Project based learning can be designed to suit the project context learning environment of students. The current advances in information technology, media, and technology play a role in instructional and learning in particular media creative. [3], [4]

Media creative presentations in the form of technology, such as the info graphic, video clips, film, images, graphics, animation and so on. This creative media is a creative content to promote moral ethics and culture promote learning life skills. It's especially for children and youth, promote good relations in the family and society. [5] It said that if the creation media used in the preparation of a project based learning for the students and will enhance access to the content they want to communicate with appropriately and to promote ethics and the audience. In the current the mainstreaming of children with special needs and normal children is a form of education that is universal. It is recognized by many parties, whether they are students, teachers, parents, educators and medical organizations concerned with education. [6]

An education for human rights equally, according to the policy of the United Nations Economic and Social. It is education that meets the needs of each individual must have the appropriate coordination. Also, when considering the need for resources. The education for children with special needs in the past are classified as special schools, or a special class requires a lot of resources and personnel. Proportion of the target audience is children with special needs with the resources it requires to operate. While inclusive education has resulted in better utilization of the available resources in the state of the world is highly competitive in terms of economy. Trade and information consider investing in a particular subject that needs to be done carefully, and requires the use of the limited available resources wisely. Investment in education for children with special needs to participate in the study is the correct way. [6], [7] But the problem is to do with how to make studying in a tertiary teaching and learning to meet the students are entitled to develop their capacity to use technology for education in the first inning. In order to have sufficient knowledge and skills to use the technology to study in the pursuit of self-knowledge has continued throughout life and promote learning in the 21 st century.

Therefore, the instructional creation media project based for mainstreaming of students can develop creative learning classes. To undertake joint activities to act according to the interests between groups of students between regular students and special needs as appropriate through creation media project based that was done. And solve problems according to the project to enhance security and promote media ethics on the other. The objectives of this research were to 1) study the direction to the instructional creation media project base for mainstreaming of undergraduate students to enhance 21st century learning. 2) To study the effects of using instructional creation media project based for mainstreaming of undergraduate 
students to enhance 21st century learning. In addition to skills for learners in the 21st century, both in the media and information technology, teamwork interaction between the regular students and special needs students. Affect the students to promote learning and lifestyle appropriately includes both of features work learning and moral to remain at full capacity to the international community following.

\section{Materials and Methods}

\subsection{Subject Selection and Criterions}

2.1.1 The sample group to study objective 1 was directors and experts that experience in special education, educational technology, creative media and higher education. The group specifically to interview key informant total of five people, to evaluate the IOC (Index of Item Objective Congruence) of five people, and the focus group of seven people by targeting qualified to graduate level courses and / or academic positions in higher education institutions.

2.1.2 The sample group to study objective 2 consisted of 61 undergraduate students; there were 54 normal students and 7 special need students, who registered the course of Ethic in 2016 academic year.

\subsection{Instrument}

The instrument used in the research following in objectives.

1) Purpose of 1 as follows: 1) in-depth interviews form, 2) IOC form to evaluate the instructional creation media project based for mainstreaming of undergraduate students to enhance 21st century learning, 3) plans of creation media project based for mainstreaming of undergraduate students to enhance 21st century learning, to brainstorm ideas for the expert focus group.

2) The tools used in objective 2 as follows: 1) the instructional creation media project based for mainstreaming of undergraduate students to enhance 21st century learning, 2) the learning achievement test of user information, media and technology, and 3) questionnaire about skills of information, media, and technology.

\subsection{Research Design}

The research design follows in objectives of research.

1) Purpose of 1; the research designs were qualitative research with in-depth interviews, and focus group and quantitative research of IOC evaluate.

2) One group pretest-posttest design was research design in objective 2.

$\mathrm{T}_{1} \quad \mathrm{X} \quad \mathrm{T}_{2}$

$\mathrm{X}$ : Experiment or Treatment

$\mathrm{T}_{1}$ : Pretest

$\mathrm{T}_{2}$ : Posttest

\subsection{Statistic}

1) Purpose of 1 as content analysis from in-depth interviews and focus group data, and mean ( $\bar{X})$ from IOC data.

2) Purpose of 2 as the statistical package was uses for mean, standard deviation, t-test dependent.

The meaning of skills for 21st century learning as information, media and technology as follows:

$4.21-5.00$ was the skills level 5

$3.41-4.20$ was the skills level 4

$2.61-3.40$ was the skills level 3

$1.81-2.60$ was the skills level 2 
$1.00-1.80$ was the skills level 1

\subsection{Methods}

The method follows in objectives of research.

1) Purpose of 1 as follows: 1) Collected data through interviews with directors and experts in special education, education technology creative media and higher education. 2) Collected data through IOC evaluate with experts in special education, education technology, creative media, and higher education. 3) Collected data through focus group by the opinions of experts.

2) Purpose of 2; the experimental group will learning by using creation media project based for mainstreaming of undergraduate students for 13 weeks, the steps as follows:

Week 1-3: Provided learner to mainstreaming. Projects scheduled events media. Identify social / community to solve problems and develop community.

Week 4-5: Offered knowledge and group activity. Instructors demonstrate examples, case studies, articles, project examples, problems to solve society / community, or to develop the community.

Week 6-8: Reviewed knowledge. The student presented a review of the knowledge gained.

Week 9: Knowledge application. Focusing on the application of knowledge in other situations, instructors emphasize that the students were aware of the content learned, and the application of learning content.

Week 10-12: The development of creative media. Planning media and choosing technology to development of the creative media.

Week 13: Evaluation. Assessing creation media projects, how to the best practices 21st century learning skills in the field of information, media and technology.

\section{Results and Discussion}

\subsection{The Instructional Creation Media Project Base for Mainstreaming of Undergraduate Students to Enhance $21^{\text {st }}$ Century Learning}

1) Elements of the teaching cadre media are as follows; 1) preparation of inclusive education, 2) community development issues or the need to carry out project work, 3) learning of learners, 4) creation media, and 5) technology. The element will find that the first element arrangements, joint learning. Hence, inclusive education must be prepared to create a positive attitude all parties. Consistent with the concept of Powell [8], stating that the students will have to identify the needs of special students, understanding normal students for mainstreaming, the contribution of special classes for students. The second element is community development issues or the need to carry out the project. A significant element of learning, the learner must have a common interest. A sense of mission shared responsibility, considering the learning of the students. Which highlighted the contributions to activities; in a community of learners helping each other members work together to resolve Improvement and Community Development Consistent with the concept of Panich [9] states that in order to promote a culture of learning in the 21st century learner must take action to keep pace with the changing world. Social change to intentionally change the way work is lifestyle changes. The learning culture is desirable to have the main ingredients. Cultural initiatives boldly dare to think of experimental culture of knowledge sharing. And creating a community of practice for the media, it is intended to offer voluntary community development. To promote ethics in media presentation technology to support learning, as part of the digital skills, also known as information, media, and technology skills are important skills of the students in the 21st century. The students with the skills of information, media, and technology information sources are available to meet the demand. Information can evaluate and select information to operate efficiently. Analysis can be used 
to convey an understanding. Valuation media and application framework used by ethical and fair. And technology effectively [2] is the last component technology environments by using technology to communicate. Technology for Inclusive Education must be accessible to everyone (Access for all) and Powell [7] presented the technology facilities contributed to the teaching and learning for students co-operated effectively and should be manage the implementation of teaching and learning in an environment with a minimum limit.

2) The processes of teaching a creation media project has six steps: 1) provided learner to mainstreaming, 2) offered knowledge and group activity, 3) reviewed knowledge, 4) knowledge application, 5) creative of media, and 6) the evaluate. The teaching consists of six main stages. Planning, preparing learners to attend classes to provide basic knowledge and group events. The students have a good attitude and a good attitude towards work. In order to provide basic knowledge and group events, the group encourages the students, and exchange ideas about course content associated with an event on community issues. Or to community development consistent with the idea of Jackson, Harpen and Jackson [10] said the study conducted jointly by the group with flexibility. A variety of activities will contribute to the knowledge of the students learning together. The application of that knowledge on to the students to be aware of the content learned. The application of learning content, a refresher on the other hand, then applies that knowledge to make the students can be evaluated. Wood [11] in his reviews that assessment. The presentation will be reviewing some of the solution. Practices have already applied in other situations. For creative development, media planning, media production choosing the technology to development of creative media. To support learning, collaborative learning, and promote the ethical conduct of the project volunteers to solve social / community, and community development. It also supports the ability to analyze the content of the media with a critical thinking. To be able to control the interpretation of media content to view or interact. [12] The final evaluation. It's based media projects, and achievement in using information technology and media in line with stating that the evaluation must be assessed by measuring joint learning based on the actual work, participation in activities. [10]

\subsection{The Effects of Using Instructional Creation Media Project Base for Mainstreaming of Undergraduate Students to Enhance $21^{\text {st }}$ Century Learning}

3.2.1 The 21st century learning as information, media, and technology of mainstreaming pre-test score in a moderate, level $3(X=2.83, S D=0.63)$ when evaluated after the trial, information, media, and technology skills are high, level $4(\bar{X}=4.06, S D=0.41)$ on each side of the intersection is a level of performance in a high level. The practice can be sorted in descending order as follows; using technology ( $\mathrm{X}$

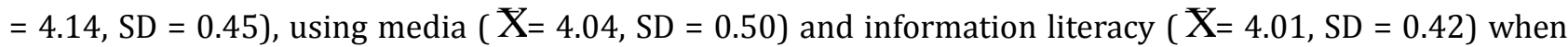
compared skills, information, media, and technology before and after experiments using statistical t-test using a confidence level of $95 \%$ in the test found that on each side, and the 2 - tailed of less than 0.05 indicates that the skills, information, media, and technology, before and after treatment with a difference.

3.2.2 Considering the learning achievement of user information, media, and technology groups found that, the learning achievement after the experiment with the higher value of 22.61 prospects develop higher percentage 43.42 by the students with special needs have higher achievement. Compared learning achievement before and after using instructional creation media project based by using statistical t-test using a confidence level of 95\%, the test found that the Sig., less than 0.05 (Sig. $=0.00$ ), indicating that the learning achievement of user information, media, and technology, students before and after school was different. The learning achievement post-test of user information, media and technology ( $\mathrm{X}=22.61$ ) than pre-test $(\mathrm{X}=7.41)$. 


\section{Conclusion}

The development of learners in the 21st century requires a process of teaching a wide variety. Instructors use teaching techniques that focus on the process that leads the students to learn on their own and the opportunities for learners' curiosity. The self-directed of them and find resources for research knowledge. [8] Integration of learning activities similar to the life skills of learners in the 21st century both in terms of knowledge of the subject matter and knowledge integration. The skills needed for learning and life skills as well as learning and innovation, life skills and work, and media and technology literacy. This will affect the students to promote learning and lifestyle appropriately. Educational management is a comprehensive education for all people. According to human rights principles special needs students receive educational opportunities to promote a culture of learning that is comparable to that of a typical learner. Teaching using a project is a learning base. It is an activity to promote a culture of learning that is consistent with 21st century learning skills so that all learners can learn the practicalities of collaborative projects. Have developed around self-knowledge, building affect the quality of life of all learners, and the propulsion of the next.

\section{References}

[1] Office of the Education Council. (2015). Nation Education (No.3) 2010. Retrieved from the website: http://www.onec.go.th/onec_web/page.php?mod=Category\&categoryID=CAT0000011.

[2] Trilling, B., \& Fadel, C. (2007). 21st Century Skills: Learning for Life in Our Times. San Francisco: Jossey-Bass.

[3] Netwong, T. (2014). Development of information technology literacy and volunteers by using blended learning and society service project based learning. Journal of Industrial Education, 13(3), 59-65.

[4] Phooma, C. (2554). Development of a U-Learning Model Using The Concepts of Knowledge Sharing in a Community of Practice and Project - Based Learning to Develop Material Science Technology Innovations for Small and Medium Enterprises. Doctoral Dissertation, Educational Communications and Technology, Department of Curriculum, Instruction and Educational Technology, Faculty of Education, Chulalongkorn University.

[5] Culture Surveillance Bureau. (2017). The Secure and Creative Media Development Fund Act 2015. Retrieved from the website: http://www.m-culture.go.th/surveillance/ewt_news.php?nid=62\&filename=index.

[6] Nimtalung, 0. (2009). Inclusive education: Access to education for all. Sakon Nakhon Rajabhat University Journal, 1(2), 39-53.

[7] Srinudech, A., Hanhuk, P., \& Sunkum, P. (2017). Device to Sustainable Inclusive Education. Retrieved from the website: https://www.l3nr.org

[8] Powell, S. (2003). Special Teaching in Higher Education: Successful Strategies for Access and Inclusion. London: Stuart Powell.

[9] Panich, W. (2016). New Learning Culture. Retrieved from the website: https://gotoknows.org

[10] Jackson, R., Harpen, K., \& Jackson, J. (2002). Effective Teaching Practices and the Barriers Limiting Their Use in Accessing the Curriculum: A Review of Recent Literature. Wakefield, MA: Center for Applied Special Technology, Inc.

[11] Wood, J. W. (2009). Practical Strategies for the Inclusive Classroom. New York: Pearson Education.

[12] Grant, M. M., \& Branch, R. M. (2005). Project-based learning in a middle school: Tracing abilities through the artifacts of learning. Journal of Research on Technology in Education. 


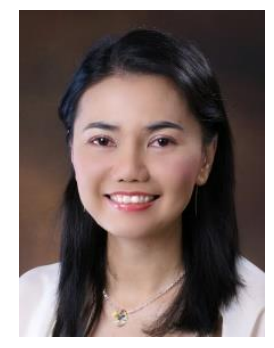

Netwong T. was born in Kalasin province, Thailand. She completed her doctor of philosophy degree in educational communications and technology on 2010. She is a lecturer at the Faculty of Science and Technology, assistant professor in information technology program, Suan Dusit University in Thailand. 